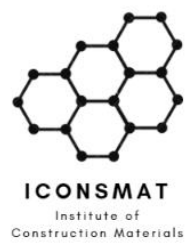

Content list available at ICONSMAT

Journal of Construction Materials

Journal homepage: www.iconsmat.com.au/publication
Article history:

Received 10 December 2020

Received in revised form

11 January 2021

Accepted 26 January 2021

Available online

4 February 2021

\title{
Petroleum Well Blowouts as a Threat to Drilling Operation and Wellbore Sustainability: Causes, Prevention, Safety and Emergency Response
}

\author{
Mohammad Reza Abdali ${ }^{1}$, Nima Mohamadian², Hamzeh Ghorbani ${ }^{3 *}$, David A. Wood ${ }^{4}$ \\ ${ }^{1}$ Department of engineering, Najafabad branch, Islamic Azad University, Najafabad, Iran \\ ${ }^{2}$ Young Researchers and Elite Club, Omidiyeh Branch, Islamic Azad University, Omidiyeh, Iran \\ $3 *$ Corresponding author: Young Researchers and Elite Club, Ahvaz Branch, Islamic Azad University, Ahvaz, \\ Iran; E: hamzehghorbani68@yahoo.com \\ ${ }^{4}$ DWA Energy Limited, Lincoln, United Kingdom
}

\begin{abstract}
Sustainability in petroleum wells drilling operation systems strongly depends on the use of sustainable materials and a set of technical and safety measures that lead to the survival and proper operation of drilling rig equipment's and personnel. Adherence to the highest levels of standards of tools, materials and methods, although always recommended as the most important option for advancing a safe drilling operation and completing the well efficiently, low risk and stable, but drilling operation is inherently a battle with underground challenges and unexpected dangers. Learning from past such well blowout events and the problems they pose to rapidly control is essential to reduce future impacts including injuries, damage and emissions. Such analysis offers guidance for adapting working practices to improve both prevention and emergency response to such incidents. The causes of blowout during drilling and the necessary technical and safety measures to adopt are reviewed, highlighting how best practices can prevent blowout incidents by improving responses to early warning signals. The particular risks associated with potential shallow gas blowouts are identified and described with the aid of a case study associated with a catastrophic blowout of an onshore well in Iran and the methods used to ultimately control it. The multiple causes of the incident relating to defects in safety systems, equipment and operating procedures are addressed. Lessons learned from the incident reveal the complexity of well control once a blowout incident has occurred and developed into a surface fire. from the stage of the incident to fire control. There is a need for further research into top-hole well kill techniques for wells in a blowout state, as drilling bottom-hole relief wells takes substantial time, during which much surface damage, resource loss and emission typically occurs.
\end{abstract}

DOI: $10.36756 / \mathrm{JCM} . \mathrm{si1} .1 \mathrm{r}$ C2021 Institute of Construction Materials

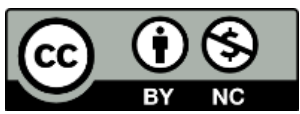

\section{Keywords:}

Wellbore sustainability, safety, blow out hazard, emergency response, well blowout 


\section{Introduction}

Drilling and exploration to extract oil and/or gas resources from subsurface reservoirs is a challenging and potentially hazardous operation because of the potentially high pressures and temperatures and flammable nature of hydrocarbons, particularly natural gas. Uncertainty about the conditions that prevail below ground, heterogeneities in sedimentary rock formations, and particularly the difficulties in predicting pore pressure behavior with depth. All act to increase the risk exposure of drilling operations [1-3]. Although seismic assessment techniques shed light on the distribution of subsurface horizons much uncertainty remains regarding the pore pressure and fluid conditions in prospective reservoir formations [4-5]. Drilling wellbores in such circumstances, in both exploration and field development scenarios, involves the possibility of encountering unexpected hazardous conditions. This requires vigilance to execute prompt and rigorous safety measures to ensure that unwanted flows of formation fluids in fluxing into wellbore are promptly addressed and inhibited [6]. It is important to ensure such safety measures and emergency response drills are regularly tested and practiced. Do so improves the ability of drilling teams to prevent loss of well control and if well blowouts do occur, they are promptly handled without injury or extensive liquid spill, gas emissions, fires and explosions.

The oil and gas industry, which has long been the focus of the whole world, and the reason is that the extracted oil and gas has changed the world. Many people did a lot of work to optimize and find important and key parameters in the oil and gas industry [40-58]. The sustainability of wellbore, materials and drilling equipment's is severely threatened by well blowouts. In order to carry out drilling operations more safely, various pre-drilling review methods have been developed for drilling contractors and rig crews. These address each stage of the well construction process ensuring that the safety requirements adopted are fit-for-purpose and rig crews are proficient at implementing them. Drill the Well on Paper (DWOP) is a pre-drilling reviewing process [7-8] and engineering analysis of a drilling operation schedule with the objective of better organizing it to improve efficiency, reduce nonproduction time and costs, and adequately consider risk management. Built upon years of operational experience and tackling challenging gas and oil fields, DWOP and other pre-drill review systems seek to ensure that all drilling crews are fully aware of their duties, the equipment available to them and provide the best practices with which to guide the drilling projects towards meeting their goals without incident or accident. DWOP also tracks risk assessment to the extent that it does not lead to loss of well control.

Potentially significant and uncontrollable volumes of can be discharged rapidly into sub-sea and land environments when a well blowout occurs. Petroleum fluids from subsurface reservoirs represent major potential pollutants [34] with multiple adverse influences on human health and ecosystems more generally [9]. Sub-sea drilling petroleum blowouts on offshore platforms are of particular environmental concern, particularly in deep water, as exemplified by the Deepwater Horizon incident in the Gulf of Mexico in 2010 [10-11]. Distribution of oil droplet contamination in some of the worst cases have been reported up to 20 meters from a suspended column of oil bubbles rising above the water extending over an area of $25 \mathrm{~km}$ [12]. Petroleum discharges into marine environments have detrimental effects on the marine ecosystems by disrupting the food chains of marine organisms for long periods. Comprehensive studies of the Gulf of Mexico ecosystem six years after the blowout of the Macondo well confirmed the continuing destructive effects of petroleum pollutants in the form of petroleum blanket deposits on deep-water sands and spongy ecosystems deep in the Gulf of Mexico [13]. Drilling operations are classified as one of the most dangerous occupations worldwide and cover a wide range of potential injuries, threats to life, environmental hazards, and negative economic consequences (show in Fig. 1). Given these threats of injury and damage from petroleum wells blowouts, it is essential to critically review and potentially upgrade safety concepts and drilling standards in order to eradicate or at least minimize the adverse consequences. Here we review the key 
technical issues and safety concerns relating to rogue wells for which control is lost and effective programs to mitigate them.

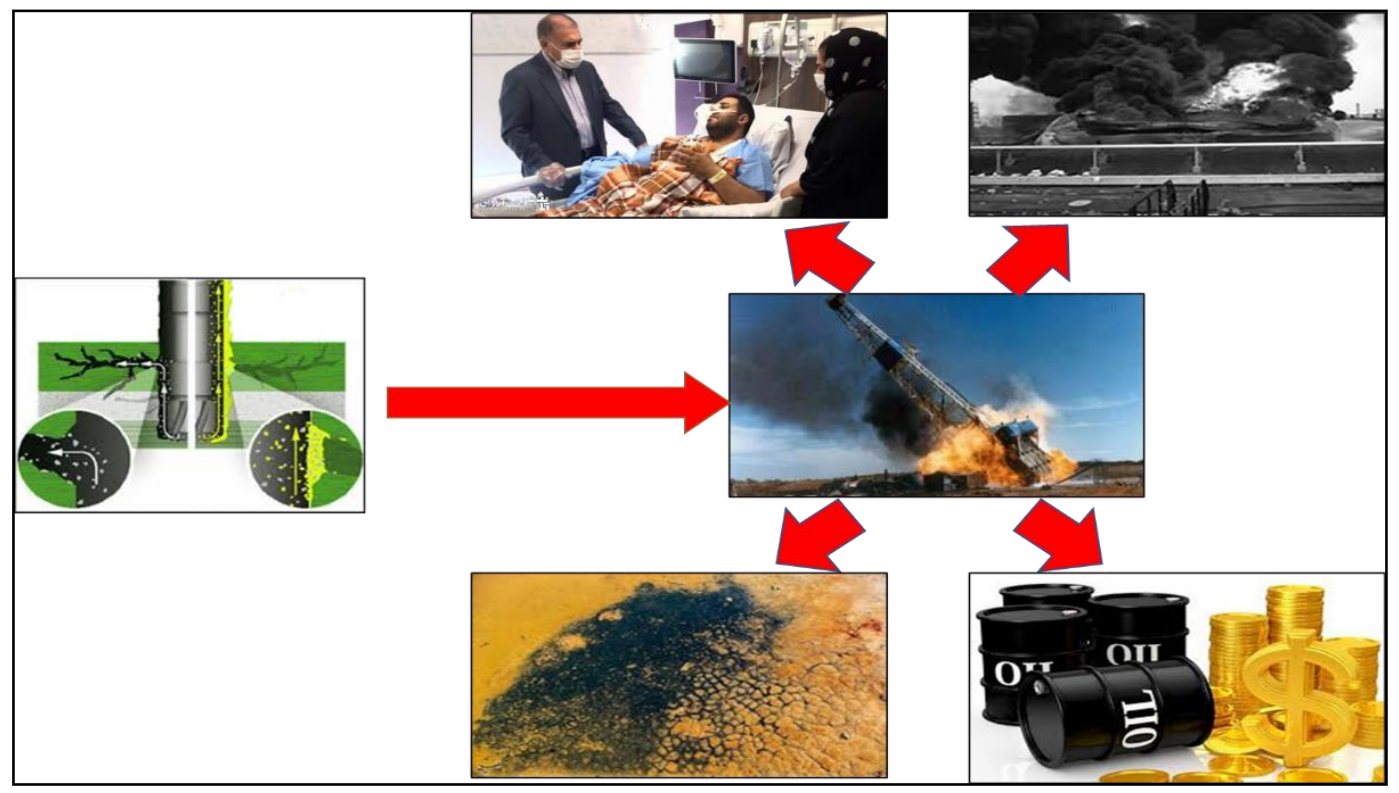

Figure 1 - Schematic displaying potential blowout consequences.

\section{Factors causing oil and gas wells to kick and potentially blow out}

Given that wellbore blowouts are one of the most dangerous and costly events to impact the petroleum drilling industry $[1,14]$, although they occur relatively infrequently, the risks of such occurrences need to be comprehensively understood. Indeed, the most catastrophic accidents in the drilling process, involving explosions and fires, are associated with blowouts. Additionally, such events lead to wastage, sometimes accumulating into millions of barrels of oil equivalent of resources, and destruction of drilling rigs and well-site equipment.

Blowout control is typically very challenging and time-consuming. Resolving the difficulties requires the deployment of costly specialist equipment [15]. A blow out is an uncontrolled influx of, gas, oil, and/or formation water from the wellbore to the surface. It occurs due to the inability of wellbore fluids to resist the fluid pressures in one or more of the formations drilled and typically existing in open-hole conditions [16]. Blowouts typically occur due to the lack of timely detection or control of fluid influx from the formation into the wellbore. There are several indications through which drilling crew can detect the occurrence of kick, is occurring, the most important of which are an increase in mud flow rate on flow line, an increase in mud volume in mud pits, flowing well while pumps are shut down, a change in the weight of drilling string, a decrease in pump pressure, an increase in pump stroke.

The initial influx flow which is referred to as a "kick" is the first event that could potentially turn into a blowout. Kicks are not infrequent events while drilling ahead in wellbores and are usually controlled by responding with an increase in the density of the drilling / wellbore fluids. Kicks can occur at any time and in any permeable formation penetrated by a wellbore, regardless of the type of operation [17]. The hydrostatic column pressure of the drilling fluid is the first line of defense against fluid influx. The drilling fluid column in the wellbore provides a hydrostatic head or pressure at the bottom hole that typically is maintained at close to balance with the formation fluids pressure. A kick is the outcome when the formation fluid pressure begins to exceed the hydrostatic pressure applied by the drilling fluid column at the influx exposure point. Early kick detection is very important for drilling crews, particularly where gas is the formation fluid, because it provides time react and make changes to the necessary adjustments to drilling fluid density (mud weight) and/or wellbore pressure [18]. Gas kicks are more 
dangerous than pressurized salt water kicks due to higher mobility of gas bubbles and their explosiveness and flammability potential. In the salt water kicks, timely reaction and application of sufficient hydrostatic column pressure will prevent the saline fluid from continues invading to the wellbore and will not pose much danger to the crew. In the gas kicks occurrence, even after stopping the gas invasion to the wellbore, due to the difference in gas density with the drilling fluid the entered gas column in the well will rise and will be a potential threat to the crew until it is completely out of the wellbore.

Any factor that interferes with the performance of the drilling fluid and limits its ability to restrain the formation fluids undermines the ability to control a kick. Lost circulation is the most common occurrence leading to inability to provide the sufficient hydrostatic column pressure [19]. Reduction of the volume and pressure of the fluids in the wellbore due to lost circulation often prompts an initial kick. If the lost circulation persists the ability to control the kick becomes more difficult.

\section{Lost circulation and blow out hazards}

Loss of circulation as some of the drilling fluid circulating in the wellbore fails to return to the surface from the wellbore annulus space while continuous pumping fluids around the well. This results in the volumes of drilling fluids in the mud tanks to drop. It is a common and serious wellbore drilling problem and is often associated with the invasion of drilling fluids into the large-scale formation fractures or underground cavities [20]. Sometimes incorrect information or anticipation of the pore pressure and fracture pressure of formation being drilled causes an inappropriate mud weight to be deployed leading to severe overpressured or underpressured conditions at the bottom hole. It is essential to calculate bottom-hole pressures taking into account the circulation density of the drilling fluid in the dynamic state [3]. Drilling into formations with substantially over-pressured drilling fluid, above the formation fracture gradient threshold will likely lead to the failure of the formation, prompting loss of circulation followed by a kick [21-22; 36-40].

\section{Shallow gas and blow out hazards}

Shallow trapped gas accumulations are a troublesome drilling problem worldwide. They usually are fed over geologic time scales from deeper natural gas reservoirs, although some are formed by in situ biogenic processes in the shallow sediments [23]. When drilling the shallow section wellbores, the overbalance hydrostatic pressure margin of drilling fluid column is usually less than during the drilling of deeper wellbore sections. Therefore, encountering a pressurized reservoir containing gas at relatively shallow depths while drilling ahead into deep formations can lead to wellbore gas invasion that is difficult to control.

More than a quarter of blowout incidents are caused by shallow gas accumulations because shallow gas kicks are much more difficult to handle compared to deeper gas kicks with the available well control methods. A general gas kick control method requires shutting in the wellhead and applying back pressure to the formation, and at the same time, establishing a slow circulation rate with a higher density drilling fluid or "kill mud". That approach circulates out the gas kick more safely from the wellbore by directing the light returning mud into separators, removing the gas and direct it towards a flare, if necessary. Circulating drilling fluids of sufficient density (higher "mud" weight) in almost all circumstances inhibits further influx of formation fluids into the wellbore. In shallow formations with low fracture pressures the action of closing in the well following a gas kick (i.e..., influx of gas into the wellbore) runs the risk of creating a high back pressure in the wellbore that will progressively fracture open-hole formations to. This sometime leads to sub-surface cross-flow of fluids from one formation to others, essentially an underground blowout into shallow formations [24]. In such cases, eventually, if the shallow formations are connected to the surface via fractures or outcrops, elevated fluid pressure will lead to surface eruptions of subsurface fluids, perhaps at multiple locations over wide areas causing environmental damage and substantial emissions. 


\section{Drilling management systems that address blow out hazards}

Drilling operations have to be conducted under robust safety management systems with available emergency response equipment operated by well-trained and practiced crews. Moreover, drilling rig equipment and blowout preventers (BOPs) have to be well maintained and frequently tested to ensure that they remain fully operational to their design specifications. There is always the danger that the pressure control systems / BOPs fail or are inappropriately overridden by misguided human interventions. Such equipment and human failings can and do sometimes result in uncontrolled flows of oil and gas reaching the surface causing severe damage and potentially igniting or catastrophically exploding destroying the drilling site with multiple injuries and deaths of drilling personnel.

Maintenance of pressure control system components, and its periodic rigorous testing, must, therefore, be performed accurately and without negligence. The operation of downhole tools, valves and wellhead equipment must be conducted in accordance with their certified operating specifications and their degree of mechanical fatigue regularly monitored and recorded. All attempts to cut corners with respect to recommended safety guidelines and international best practices should be strictly resisted and avoided. Well-site and engineering management staff training, awareness and motivation to comply with a robust safety-minded culture is essential. Drilling operations safety and risk managers have the duty to ensure that all operations staff are fully aware their roles and responsibilities when emergencies occur in the face of sub-surface well control hazards.

\section{Issues associated with Inaccurate information and human error}

Deficiencies in the availability of correct information regarding the prevailing pore pressures of the formations being drilled can lead to inappropriate well designs and implementation of flawed drilling programs. Moreover, the dissemination of inaccurate information and incorrect assumptions regarding subsurface conditions can lead to complacency regarding the subsurface risks being taken, thereby inadvertently compromising operational safety. Inaccurate information on critical formation pressures and drilling with insufficient mud weight or with insufficiently robust wellheads and BOPs are relatively common issues encountered. Also, the incorrect determination of appropriate casing points and placement of casing shoes can lead to hazardous pressure gradient occurring in the deeper sections yet-to-be drilled. Sometimes tripping drill strings in and/or out of the wellbore too rapidly can lead to suction effects that promote formation fluid inflow to a wellbore. Running inappropriate cement formulations that fail to isolate high-pressure formations can also lead ultimately to kicks and blowouts [3, 25-26]. All such situations can be attributed to human error and/or inadequate safety scenario planning during planning stages and ongoing drilling operations.

\section{Safety and technical actions used to prevent and/or mitigate blowouts}

\section{Exploratory drilling in unknown areas}

Exploratory drilling in frontier areas where there is no experience of underground conditions pose substantial challenges for drilling teams. The occurrence of kicks or lost circulation should, in such circumstances, be expected at any time and depth. The experienced drilling team must consider all safety requirements to meet these challenges. The following includes some of the routinely adopted measures.

a) Continuous provision of hydrostatic pressure. Over-balanced drilling (OBD) is the most common method adopted for such conditions. The hydrostatic pressure of drilling fluid column in the borehole is continuously adjusted to maintain it approximately 100 to 150 psi above bottom-hole formation pressure. If this is successfully maintained, kicks leading to potential blowouts will not occur. Therefore, one of the main tasks of mud engineers is 
to continue design and provide appropriate drilling fluid designs and densities to achieve this.

b) Early warning monitoring system. Early warning gas detection systems in the mud-logging unit linked to alarms on the drill floor should be in service with minimum delay detection times. In addition, mud-pit level evaluation, fluid loss trend monitoring, drilling parameter and performance collectively help to reveal early-warning signs of pending drilling hazards. Rapid and appropriate responses by skilled monitoring personnel can save critical time in dealing with kicks / lost circulation with minimal delays. Such systems and monitoring staff require ongoing and regular performance monitoring with specified senior managers and engineers made accountable for that occurring.

c) Experienced drilling team. An experienced drilling team requires detailed knowledge of the equipment, operating procedures, and, where possible, comprehensive understanding of local sub-surface conditions and known problematic formations. Recognizing the oscillating trends in multiple drilling parameters commonly associated with kicks and/or lost circulation can provide experienced drilling crews with vital early warning signs that could be overlooked by inexperienced or distracted drilling staff. Experience and attention to detail is often sufficient to pick up on pre-incident warning sings, such as unreasonable changes in pressure or pump strokes to quickly recognize and anticipate kicks and thereby prevent them developing into blow-out events.

d) Another key factor in preventing blowouts during the drilling of oil and gas wells is the periodic and regular rigorous BOP testing and maintenance. This ensures that all components of the BOP are fully functional and are operating correctly in automatic and manual override modes.

\section{Responding to occurrences of drilling fluid lost circulation}

The availability of sufficient water resources to make up adequate volumes of drilling fluid is always essential before drilling operations begin, because future potential mud losses could require more weighted drilling fluid to be required at short notice [20-21, 27-28]. When a drilling operation encounters a loss of circulation problem, the following sequential steps are necessary.

a) Ensuring that drill-site water storage reservoirs and drilling fluid tanks are kept as full as possible;

b) Availability of lost circulation pills to deploy at short notice. Lost circulation material (LCM) pumped into a wellbore experiencing lost circulation can control or at least reduce drilling fluid losses into fractured formations. LCM such as mica, shell fish, nut shells and other fibrous materials are often sufficiently effective to control loss circulation. By spotting such LCM on or close to the problematic fractured/ porous zone experiencing mud losses can often eliminate mud losses. After the drilling operation, the reservoir porous spaces that were blocked with LCM to control mud losses can be flushed with an appropriate acid or chemical wash restore permeability and production rate from an effected reservoir zone. 
c) Ability to run magnesia-based cement plug(s). If the intensity of mud losses is high and cannot be controlled with LCM, then a magnesite or normal drilling cement plug may be required to control the lost circulation. Magnesite is a quick-setting magnesia cement that dissolves completely in acid. It is a suitable candidate cement material for use as a temporary lost-circulation barrier in productive reservoir zones, as it avoids any permanent damage to the plugged zone from insoluble materials.

\section{Avoiding and controlling shallow gas}

High-resolution geophysical surveys, including high-frequency seismic techniques, can readily detect the presence of shallow gas accumulations. By identifying and avoiding high-risk areas based on the interpretation of such surveys, drilling sites can be selected with a low risk of encountering shallow gas during the drilling operations.

In areas exposed to shallow gases where it is not possible to move the drilling location sufficiently to avoid them, it is necessary to follow a carefully customized well design. The steel casing and cement sheath needs to be run and pressure tested close to the top of the risky layer to secure the wellbore down to that depth point. Drilling out of that casing shoe directly into the shallow gas zone enables the drill crew to be prepared with well control responses appropriate for controlling shallow gas kicks.

\section{Wellbore management and human resources}

A comprehensive maintenance program with regular inspections, certifications of all vulnerable equipment is an essential component of best drilling practices. Moreover, timely replacement of the tools that are more prone to fatigue and damage can minimize the risk of equipment / tool failures that have the potential to exacerbate loss of well control during drilling operations [24, 29]. Any inefficiencies or defective components in the BOP systems used in oil and gas wellbores can have irreparable consequences. It is therefore essential to ensure that the operation of these systems is demonstrated to be reliable at all times [30]. Continuous training and implementation of periodic simulated tests also play an important role in reducing the damage potentially caused by human error or complacency. Situation awareness of the rig operations crew needs to be maintained at a high level of awareness to ensure the highest possible safety standards are applied to all drilling operation [31, 35].

\section{Regular periodic "BOP Drill" maneuvers to ready for instant reaction}

One of the most effective ways to reduce the catastrophic damage and costs of wellbore blowout hazards is to train drilling rig personnel to rapidly diagnosis well control hazards. Such skills are best learned through the regular drilling and emergency response simulations and exercises. In such exercises and routine BOP tests the entire drilling team becomes better aware of the hazards and their specific roles in emergency situations. Successful rapid response needs to be well coordinated and motivated with good management commitment and direct involvement.

\section{Case study of blow out control in an onshore well}

This case study of a significant blow out event describes its causes and the responses taken to eventually control it. There are many lessons to learn from this serious incident. It occurred in 2010 and was provisionally described at that time [32-33]. It occurred in an onshore well in western Iran and is considered here from the perspective of technical and safety measures adopted to control the fire caused by an explosion of the escaping hydrocarbons. In particular, the lessons to be learned regarding fire response and control experiences associated with this event are assessed. 


\section{Naft Shahr oil field location}

The Naft Shahr oil field is located $100 \mathrm{~km}$ northwest of Ilam, $225 \mathrm{~km}$ southwest of Kermanshah and 60 $\mathrm{km}$ from Qasr Shirin (Fig. 2). This oil field was discovered in 1923 with the reservoirs located in a prominent anticlinal structure. At present, the Naft Shahr field is the only oil field being produced in Kermanshah province. It contains approximately 692 million barrels of crude oil resources with substantial natural gas resources within its gas cap. This field is of special importance because it shares a reservoir with an adjacent Iraqi oil field. A blowout and explosion occurred in well Naft Shahr\#24.

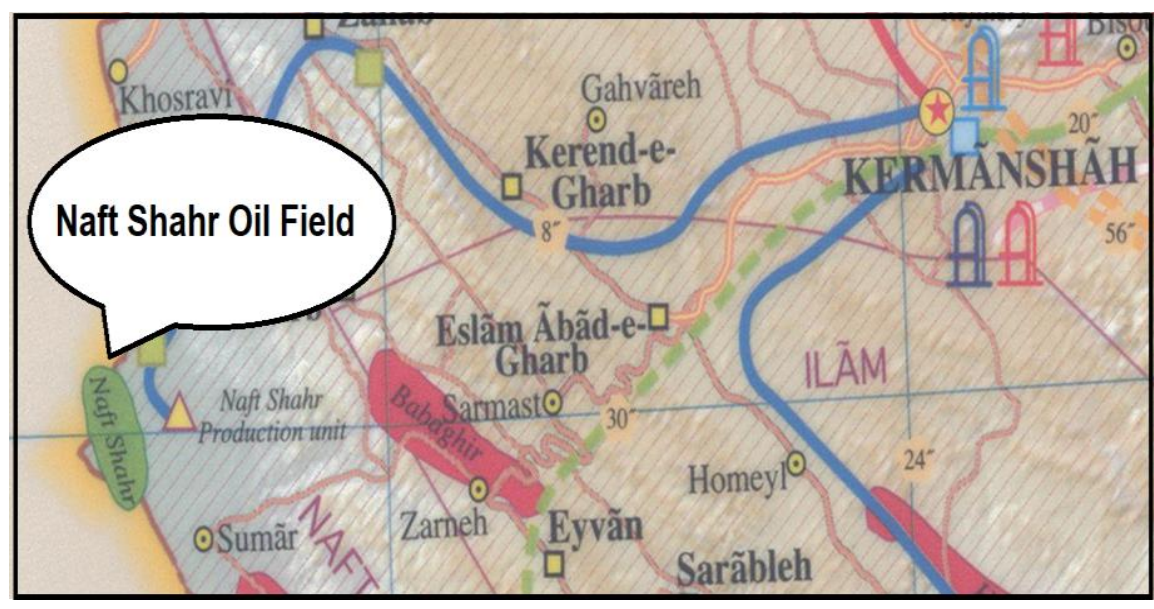

Figure 2 - Geographical location of Naft Shahr oil field in Western Iran.

\section{Description of the blow out in well \# 24}

The event occurred beginning on May 29, 2010, during the drilling operations within the $121 / 4$ " hole at a depth of 615 meters (Fig. 3). The section was being drilled with a high density (140 PCF) drilling fluid to overcame with the high pressure evaporite layers within the Gachsaran formation (the cap rock to the reservoir). The drilling crew was suddenly confronted with a complete loss of return flow of drilling fluids. This was soon followed by rapid inflow of gas due to the failure of an uncased formation containing shallow gas (i.e., unexpected cap rock zone above the known Asmari reservoir zone developed and produced for many decades).

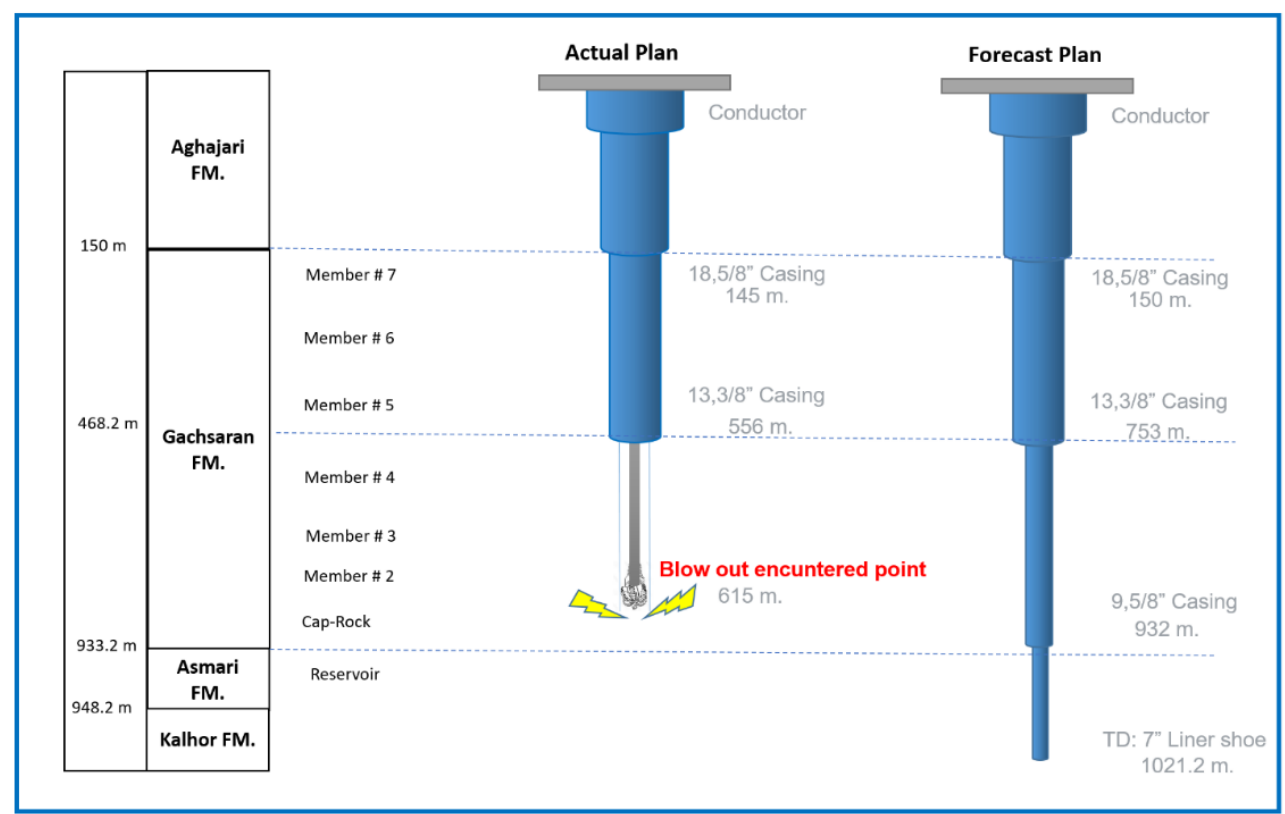

Figure 3 - Naft Shahr \#24 wellbore schematic identifying the blowout depth in a gas zone at $615 \mathrm{~m}$ depth within the Gachsaran cap rock (visualized from reference [32]). 
Once the zone in the cap rock Gachsaran formation became fractured by the high hydrostatic head of the drilling fluid in the wellbore, the return flow of the mud to the surface ceased. As the fluid level dropped in the well gas from the formation rapidly reduced the hydrostatic head within the annulus zone of the wellbore. The intensity and rapidity of the gas invasion into the wellbore meant that the rig crew had little time to react to control the well and failed to respond quickly enough to do so. A large explosion occurred as rapidly upward migrating gas reached the surface via the wellbore annulus. This explosion killed the rig-floor tool pushers, the driller and his assistant, as they were belatedly attempting to activate the BOP system through manual handwheels after the became aware that the automated hydraulic BOP system had failed. In a very short space of time, the flames completely engulfed the drilling rig and a huge volume of hydrocarbons erupting through the wellhead continued to feed the fire spread across the surface site without interruption (Fig. 4). The temperature of the fire across the surface site reached $600^{\circ} \mathrm{C}$, making it impossible for fire fighters to approach.

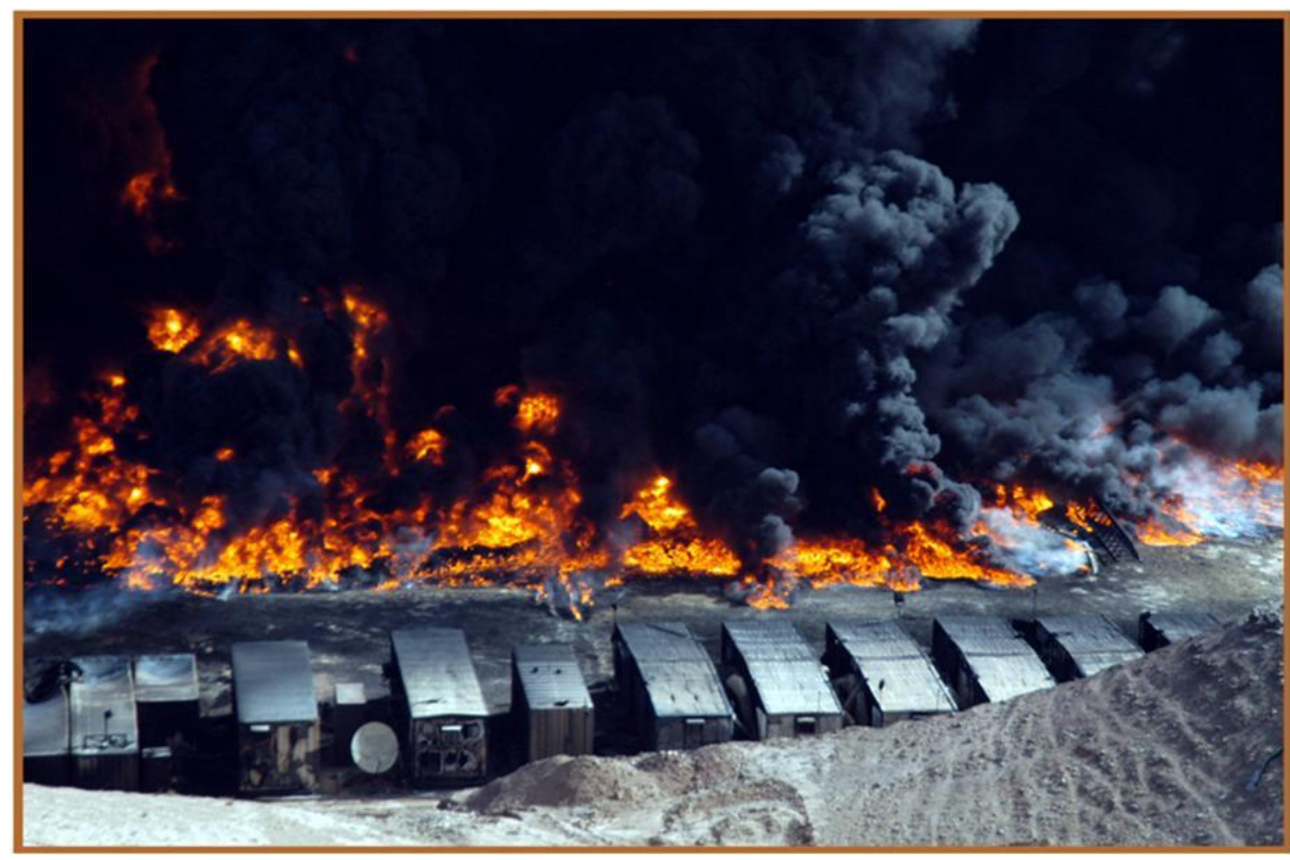

Figure 4 - View of explosion and fire engulfing the drilling rig and surface site of Naft Shahr \#24 well in May 2010.

Firefighting teams were dispatched to the well site shortly after the incident was reported. Massive uncontrollable influx of gas prevented the fire control teams from making close approaches to the fire and hindered their assessment for selecting an appropriate fire control method. The well engineering and fire control teams decided to attempt two methods simultaneously: 1) attempting to kill the well from above through the wellhead; and, 2) kill the blowout in the subsurface directly into the problem zone by drilling relief wells. Due to the high temperature and the presence of molten steel and large pools of spilled hydrocarbons across the surface site, the initial focus was to attempt to kill the flow of gas in the subsurface. Two drilling rigs were deployed to drill relief wells from nearby existing well sites (Fig. 5) at distance of $600 \mathrm{~m}$ and about $1 \mathrm{~km}$ away from the Naft Shahr \#24 well. The objectives of the two directional relief wells were to reach the subsurface wellbore trajectory of Naft Shahr \#24 and kill the flow of gas into it by injecting heavy drilling fluid from the relief wells. 


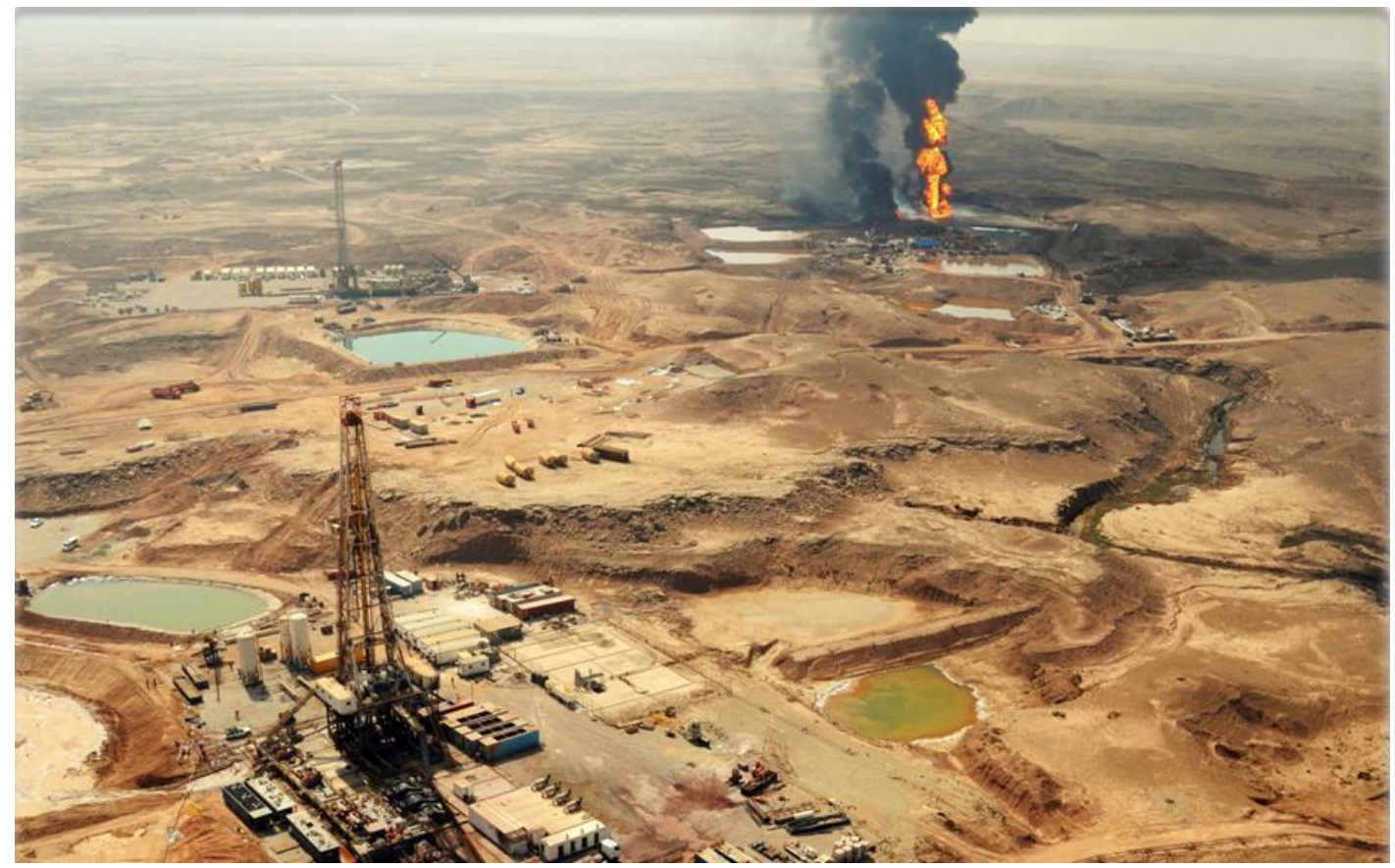

Figure 5 - Two drilling rigs located on existing nearby well sites in the process of drilling directional relief wells towards the trajectory of the Naft Shahr \#24 well (surface site seen burning) in attempts to kill the flow of gas from the problematic.

Simultaneously, while the directional relief wells were being drilled, firefighting crews made an attempt to approach the fire on the surface site by creating a cooling umbrella spaying water pumped under pressure to reduce the ambient temperature of the area surrounding the burning zone. One of the biggest challenges in this area was removing a large amount of destroyed and melted equipment from the rig structure. In order for the blowout control team to approach the wellhead it was necessary to direct flames of the fire to a greater height. This was achieved by installing a 56 -inch conductive exhaust pipe equipped with stinger. Several trial-and-error plans were trialed to design and install an effective exhaust pipe system with an appropriate stinger geometry to achieve leak-free placement around the wellhead. Finally, after 38 days, one of the directional relief wells reached the trajectory of Naft Shahr \#24 wellbore. This enabled the problem well to finally be killed in the subsurface by injecting heavy mud into it via the relief wellbore. The amount of water and mud consumed for controlling the blowout in this well were 7800 and 6300 bbl, respectively.

\section{Safety experiences and hazards in the surface killing process of well \# 24}

Although time is of the essence in controlling wellbore fires in order to avoid burning and wasting large quantities of gas and the emissions and pollution that causes, safety considerations should not be underestimated. In the case of shallow gas blowouts, closing the well is typically not a reasonable option for well control, because the increased back pressure on the drilled formations in the shut-in wellbore will cause the weak surface formations to fracture and fail. In the Naft Shahr \#24 blowout incident there were additional special conditions to take into account, including gas leakage from surface fractures in the ground surrounding the wellhead. Extremely high temperatures, reaching about $600^{\circ} \mathrm{C}$ near the blazing well posed very high risks to any firefighting team attempting to closely approach the fire. In addition, there was a risk of injury from burning debris and potential surface-site explosions associated with attempts to implement a top kill method through the well head. In addition to the four-rig crew killed in the initial explosion, ten surface personnel and including some firefighters were injured by the ensuing fire. Some of those injuries were assessed to be influenced by insufficient experience the safety department staff in adequately taking control of the burning site. 


\section{Lessons learned from the Naft Shahr \#24 blowout}

- Update and maintain rapid warning systems on the drill floor to detect gas kicks,

- Inspect, maintain and test of blow out preventer systems regularly,

- Establish emergency procedures for controlling shallow gas kicks,

- Retain exhaust pipes and stinger systems for rapid deployment to rig fires,

- Conduct regular drill crew training and rapid response exercises of the well control teams.

In case of structural damage to the building facilities around the well, environmental methods of reconstruction can also be taken into consideration as well [59-66].

\section{Conclusions}

To improve the safety performance of gas and oil drilling operations with respect to effective response to kicks and preventing well blowouts, it is essential to conduct regular and adequate training of drill rig and well site crews concerning blowout hazards and how to respond rapidly to prevent them or mitigate their impacts. Appropriate response and prevention equipment need to be available and regularly maintained and tested to ensure that it is effective. Also, access to all emergency equipment should be easy. These basic measures can and do substantially reduce injuries, damage, spill and emissions. More studies are required to improve the control procedures of well blowouts from the surface well head when such incidents develop into surface fires. Current top-hole methods expose emergency response personnel to high risks of injury. The bottom-hole approach to killing a well in the subsurface, at the problem formation, by drilling relief well(s) is effective but takes substantial time to deploy rigs and drill to the affected subsurface location.

\section{Declarations}

The authors confirm that they have no conflicts of interest and have received no institutional funding associated with this research.

\section{Nomenclature}

$\begin{array}{lll}\text { BOP } & = & \text { Blow Out Prevent } \\ \text { DWOP } & \quad \text { Drill the Well on Paper } \\ \text { PCF } & = & \text { Pound per Cubic Feet } \\ \mathrm{KM} & = & \text { Kilo Meters } \\ \mathrm{bbl} & = & \text { Barrel }\end{array}$




\section{References}

[1] Aliabadi, M., \& Mohammadfam, I. Root causes analysis of the Blow out of oil and gas wells in the drilling industry using Bow-Tie Analysis. Iran Occupational Health, 2019; 15(6), 16-24. Doi: http://ioh.iums.ac.ir/article-1-2127-en.html .

[2] Tamima N, Laboureura DM. Mentzera RA, Hasanb AR, Mannana MS. A framework for developing leading indicators for offshore drill well blowout incidents. Proc Saf Environ Protect. 2017;106:256-62.

[3] Mohamadian, N., Ghorbani, H., Wood, D. A., \& Hormozi, H. K. Rheological and filtration characteristics of drilling fluids enhanced by nanoparticles with selected additives: an experimental study. Advances in Geo-Energy Research, 2(3), 228-236. 2018. Doi: https://core.ac.uk/download/pdf/229382392.pdf.

[4] Freeman, B., Boult, P. J., Yielding, G., \& Menpes, S. Using empirical geological rules to reduce structural uncertainty in seismic interpretation of faults. Journal of Structural Geology, 32(11), 16681676. 2010. Doi: https://doi.org/10.1016/i.jsg.2009.11.001.

[5] Kosloff, D. D., \& Sudman, Y. Uncertainty in determining interval velocities from surface reflection seismic data. Geophysics, 67(3), 952-963. 2002. Doi: https://doi.org/10.1190/1.1484537.

[6] Grace, R. D. Blowout and well control handbook: Gulf Professional Publishing. 2017.

[7] Nwokoma, P., Knobben, X. Rethinking the Typical Line-Item DWOP Exercise: Does it Present a Complete Picture? SPE-184621-MS. SPE/IADC Drilling Conference and Exhibition, 14-16 March, 2017a. The Hague, The Netherlands. 11pages. https://doi.org/10.2118/184621-MS

[8] Nwokoma, P., Knobben, X. Project management approach to DWOP exercise provides a more holistic view of rig performance. Drilling Contractor 2017b. https://www.drillingcontractor.org/projectmanagement-approach-to-dwop-exercise-provides-a-more-holistic-view-of-rig-performance-42536 [Accessed 18 Nov 2020]

[9] Cuypers, C., Pancras, T., Grotenhuis, T., \& Rulkens, W. The estimation of PAH bioavailability in contaminated sediments using hydroxypropyl- $\beta$-cyclodextrin and Triton X-100 extraction techniques. Chemosphere, 46(8), 2002, 1235-1245. Doi: https://doi.org/10.1016/S0045-6535(01)00199-0.

[10] BP. Deepwater Horizon Accident Investigation Report, September 8, 2010 https://www.bp.com/content/dam/bp/business-sites/en/global/corporate/pdfs/sustainability/issuebriefings/deepwater-horizon-accident-investigation-report.pdf [Accessed 18 November 2018]

[11] U.S. Chemical Safety Board. CSB Investigation into the Macondo Disaster Finds Offshore Risk Management and Regulatory Oversight still Inadequate in Gulf of Mexico. 2016 Final report. https://www.csb.gov/the-us-chemical-safety-boards-investigation-into-the-macondo-disaster-findsoffshore-risk-management-and-regulatory-oversight-still-inadequate-in-gulf-of-mexico/ [Accessed 18 Nov 2020]

[12] Boehm, P. D., \& Fiest, D. L. Subsurface distributions of petroleum from an offshore well blowout. The Ixtoc I blowout, Bay of Campeche. Environmental Science and Technology, 1982, 16(2), 67-74. Doi: https://doi.org/10.1021/es00096a003.

[13] Joye, S. B., Bracco, A., Özgökmen, T. M., Chanton, J. P., Grosell, M., MacDonald, I. R., Cordes, E. E., Montoya, J. P., \& Passow, U. The Gulf of Mexico ecosystem, six years after the Macondo oil well 
blowout. Deep Sea Research Part II: Topical Studies in Oceanography, 129, 4-19. 2016. Doi: https://doi.org/10.1016/j.dsr2.2016.04.018.

[14] Paturu, S. Sea level gas separator of oil well effluent with incorporated emergency measures upon a well blow-out. In: Google $2019 . \quad$ Doi: https://patents.google.com/patent/US20190234185A1/en .

[15] Bergan, H. H., \& Naseri, M. Well control operation in the arctic offshore: a qualitative risk model. Paper presented at the Proceedings of the International Conference on Port and Ocean Engineering Under Arctic Conditions, 2015. Doi: https://trid.trb.org/view/1435140.

[16] Liu, R., Hasan, A. R., Ahluwalia, A., \& Mannan, M. S. Well specific oil discharge risk assessment by a dynamic blowout simulation tool. Process Safety and Environmental Protection, 103, 183-191. 2016. Doi: https://doi.org/10.1016/j.psep.2016.06.037.

[17] Islam, R., Khan, F., \& Venkatesan, R. Real time risk analysis of kick detection: testing and validation. Reliability Engineering and System Safety, 161, 25-37. 2017. Doi: https://doi.org/10.1016/j.ress.2016.12.014.

[18] Chung, S., Kim, S., \& Yang, Y. Use of hazardous event frequency to evaluate safety integrity level of subsea blowout preventer. International Journal of Naval Architecture and Ocean Engineering, 8(3), 2016, 262-276. Doi: https://doi.org/10.1016/j.ijnaoe.2016.03.005.

[19] Sabah M., Mehrad, M., Ashrafi, S.B., Wood, D.A., Hybrid machine learning algorithms to enhance lost-circulation prediction and management in the Marun oil field. Journal Petroleum Science Engineering. 2020. In Press.

[20] Elkatatny, S., Ahmed, A., Abughaban, M., \& Patil, S. Deep Illustration for Loss of Circulation While Drilling. Arabian Journal for Science and Engineering, 1-17. 2020. Doi: https://link.springer.com/article/10.1007/s13369-019-04315-6.

[21] Albattat, R., \& Hoteit, H. Modeling yield-power-law drilling fluid loss in fractured formation. Journal of Petroleum Science and Engineering, 182, 2019, 106273. Doi: https://doi.org/10.1016/i.petrol.2019.106273.

[22] Idress, M., \& Hasan, M. L. Investigation of different environmental-friendly waste materials as lost circulation additive in drilling fluids. In: Springer. 2020. Doi: https://link.springer.com/article/10.1007/s13202-019-00752-z.

[23] Ardus, D., \& Green, C. Safety in Offshore Drilling: The Role of Shallow Gas Surveys, Proceedings of an International Conference (Safety in Offshore Drilling) Organized by the Society for Underwater Technology and Held in London, UK, April 25 \& 26, 1990 (Vol. 25): Springer Science \& Business Media. 2012.

[24] Sneddon, A., Mearns, K., \& Flin, R. Stress, fatigue, situation awareness and safety in offshore drilling crews. Safety Science, 56, 80-88. 2013. Doi: https://doi.org/10.1016/j.ssci.2012.05.027.

[25] Mohamadian, N., Ghorbani, H., Wood, D. A., \& Khoshmardan, M. A. A hybrid nanocomposite of poly (styrene-methyl methacrylate-acrylic acid)/clay as a novel rheology-improvement additive for drilling fluids. Journal of Polymer Research, 26(2), 33. 2019. Doi: https://link.springer.com/article/10.1007\%2Fs10965-019-1696-6. 
[26] Mohamadian, N., Ramhormozi, M. Z., Wood, D. A., \& Ashena, R. Reinforcement of oil and gas wellbore cements with a methyl methacrylate/carbon-nanotube polymer nanocomposite additive. Cement and Concrete Composites, 114, 2020, 103763. Doi: https://doi.org/10.1016/j.cemconcomp.2020.103763.

[27] Gamal El-Shamy A. New carbon quantum dots nano-particles decorated zinc peroxide (Cdots/ZnO2) nano-composite with superior photocatalytic efficiency for removal of different dyes under UV-A light. Synthetic Metals. 2020 Sep 1;267:116472. Doi: https://doi.org/10.1016/j.synthmet.2020.116472.

[28] Vipulanandan C, Mohammed A. Effect of drilling mud bentonite contents on the fluid loss and filter cake formation on a field clay soil formation compared to the API fluid loss method and characterized using Vipulanandan models. Journal of Petroleum Science and Engineering. 2020 Jun 1;189:107029. Doi: https://doi.org/10.1016/j.petrol.2020.107029.

[29] He, Y., Fan, Y., Wu, P., Xia, C., Huang, J., Wu, J., Qian, L., \& Liu, X. Fatigue life optimization towards rubber core sealing surface of under-balanced drilling rotating blowout preventer. Engineering Failure Analysis, 117, 2020, 104965. Doi: https://doi.org/10.1016/j.engfailanal.2020.104965.

[30] Dui, H., Zhang, C., \& Zheng, X. Component joint importance measures for maintenances in submarine blowout preventer system. Journal of loss prevention in the process industries, 63, 2020, 104003. Doi: https://doi.org/10.1016/j.jp.2019.104003.

[31] Sneddon, A., Mearns, K., \& Flin, R. Situation awareness and safety in offshore drill crews. Cognition, Technology and Work, 8(4), 255-267.2006. Doi: https://link.springer.com/article/10.1007/s10111-0060040-1.

[32] Makvandi. Sahbazi, K., Bahmani, H. Blowout Control Operations in one of The Iranian Wells. SPE148592-MS. SPE/IADC Middle East Drilling Technology Conference and Exhibition, 24-26 October, 2011. Muscat, Oman. 11 pages. https://doi.org/10.2118/148592-MS

[33] Makvandi. Sahbazi, K., Bahmani, H. The Great Achievement in Well Control of one of The Iranian Wells. SPE-144508-MS. SPE/IADC Middle East Drilling Technology Conference and Exhibition, 24-26 October, 2011. Muscat, Oman. 13 pages. https://doi.org/10.2118/144508-MS

[34] Huang, X.-D., El-Alawi, Y., Gurska, J., Glick, B. R., \& Greenberg, B. M. A multi-process phytoremediation system for decontamination of persistent total petroleum hydrocarbons (TPHs) from soils. Microchemical Journal, 81(1), 139-147. 2005. Doi: https://doi.org/10.1016/i.microc.2005.01.009

[35] Lage, A.C.V.M., Jacinto, C.M.C., Martins, F.S.B., Vanni, G.S., Santos, O.L.A., \& Moreiras, J.R.F. Blowout Contingency and Risk-Reduction Measures for High-Rate Subsea Gas Wells in Mexilhao. IADC/SPE 99164. Drilling Conference Miami,Florida, U.S.A., 21-23 February 2006, 13 pages. Doi: https://doi.org/10.2118/99164-MS

[36] Davoodi S, SA AR, Rukavishnikov V, Minaev K. Insights into application of acorn shell powder in drilling fluid as environmentally friendly additive: filtration and rheology. International Journal of Environmental Science and Technology. 2020 Aug 9:1-4. Doi: https://link.springer.com/article/10.1007/s13762-020-02880-0 
[37] Ghaderi S, Haddadi SA, Davoodi S, Arjmand M. Application of sustainable saffron purple petals as an eco-friendly green additive for drilling fluids: A rheological, filtration, morphological, and corrosion inhibition study. Journal of Molecular Liquids. 2020 Oct 1;315:113707. Doi: https://doi.org/10.1016/i.molliq.2020.113707

[38] Davoodi S, SA AR, Soleimanian A, Jahromi AF. Application of a novel acrylamide copolymer containing highly hydrophobic comonomer as filtration control and rheology modifier additive in waterbased drilling mud. Journal of Petroleum Science and Engineering. 2019 Sep 1;180:747-55. Doi: https://doi.org/10.1016/i.petrol.2019.04.069

[39] Davoodi S, SA AR, Jamshidi S, Jahromi AF. A novel field applicable mud formula with enhanced fluid loss properties in high pressure-high temperature well condition containing pistachio shell powder. Journal of Petroleum Science and Engineering. 2018 Mar 1;162:378-85. Doi: https://doi.org/10.1016/j.petrol.2017.12.059

[40] Mohammadian, N., \& Ghorbani, H., 2015. An investigation on chemical formation damage in Iranian reservoir by focus on mineralogy role in shale swelling potential in Pabdeh and Gurpi formations. Advances in Environmental Biology, vol:9(4), 161-166, Doi: http://www.aensiweb.net/AENSIWEB/aeb/aeb/2015/March/161-166.pdf

[41] Ghorbani, H., Moghadasi, J., Dashtbozorg, A., \& Kooti, S., 2017. Developing a New Multiphase Model for Choke Function Relation for Iran's Gas Wells. American Journal of Oil and Chemical Technologies, 194-202.

[42] Darvishpour, A., Sefiabad, M. C., Wood, D. A., \& Ghorbani, H., 2019. Wellbore stability analysis to determine the safe mud weight window for sandstone layers. Petroleum Exploration and Development, 46(5), 1031-1038. Doi: https://doi.org/10.1016/S1876-3804(19)60260-0 .

[43] Mohamadian, N., Ghorbani, H., Wood, D. A., \& Hormozi, H. K., 2018. Rheological and filtration characteristics of drilling fluids enhanced by nanoparticles with selected additives: an experimental study. Advances in Geo-Energy Research, vol:2(3), 228-236, Doi: https://core.ac.uk/download/pdf/229382392.pdf.

[44] Ghorbani, H., \& Moghadasi, J., 2014. Development of a New Comprehensive Model for Choke Performance Correlation in Iranian Oil Wells. Advances in Environmental Biology, vol:8(17), 877-882, Doi: http://www.aensiweb.net/AENSIWEB/aeb/aeb/September\%202014/877-882.pdf .

[45] Ghorbani, H., Moghadasi, J., Mohamadian, N., Mansouri Zadeh, M., Hezarvand Zangeneh, M., Molayi, O., \& Kamali, a. 2014b. Development of a New Comprehensive Model for Choke Performance Correlation in Iranian Gas Condensate Wells, Advances in Environmental Biology 8(17):308-313. doi: https://www.researchgate.net/publication/308786325 Development of a New Comprehensi ve Model for Choke Performance Correlation in Iranian Gas Condensate Wells

[46] Ghorbani, H., Moghadasi, J., Dashtbozorg, A., \& Abarghoyi, P. G., 2017. The Exposure of New Estimating Models for Bubble Point Pressure in Crude Oil of One of The Oil fields in Iran. American Journal of Oil and Chemical Technologies, 178-193.

[47] Mohamadian, N., Ghorbani, H., Wood, D. A., \& Khoshmardan, M. A., 2019. A hybrid nanocomposite of poly (styrene-methyl methacrylate-acrylic acid)/clay as a novel rheology-improvement additive for drilling fluids. Journal of Polymer Research, vol:26(2), 33, Doi: https://link.springer.com/article/10.1007\%2Fs10965-019-1696-6. 
[48] Ghorbani H, Moghadasi J, Wood DA., 2017. Prediction of gas flow rates from gas condensate reservoirs through wellhead chokes using a firefly optimization algorithm. Journal of Natural Gas Science and Engineering, 45: 256-271. Doi: https://doi.org/10.1016/i.jngse.2017.04.034

[49] Farsi, M., Barjouei, H.S., Wood, D.A., Ghorbani, H., Mohamadian, N., Davoodi, S., Nasriani, H.R. and Ahmadi Alvar, M. 2021. Prediction of Oil Flow Rate Through Orifice Flow Meters: Optimized MachineLearning Techniques. Measurement, p.108943. Doi: https://doi.org/10.1016/i.measurement.2020.108943.

[50] Ghorbani H, Wood DA, Choubineh A, Tatar A, Abarghoyi PG, Madani M, Mohamadian N., 2018. Prediction of oil flow rate through an orifice flow meter: Artificial intelligence alternatives compared, Petroleum. Doi: https://doi.org/10.1016/j.pet/m.2018.09.003.

[51] Ghorbani H, Wood DA, Moghadasi J, Choubineh A, Abdizadeh P, Mohamadian N., 2019. Predicting liquid flow-rate performance through wellhead chokes with genetic and solver optimizers: an oil field case study. Journal of Petroleum Exploration and Production Technology, 9(2): 1355-1373. Doi: https://doi.org/10.1007/s13202-018-0532-6.

[52] Rashidi, S., Mohamadian, N., Ghorbani, H., Wood, D. A., Shahbazi, K., \& Ahmadi Alvar, M., 2020. Shear modulus prediction of embedded pressurize salt layers and pinpointing zones at risk of casing collapse in oil and gas wells. Journal of Applied Geophysics, 104205. Doi: https://doi.org/10.1016/i.jappgeo.2020.104205.

[53] Ghorbani H, Wood DA, Choubineh A, Mohamadian N, Tatar A, Farhangian H, Nikooey, A., 2020. Performance comparison of bubble point pressure from oil PVT data: Several neurocomputing techniques compared, Experimental and Computational Multiphase Flow, 2(4): 225-246. Doi: https://doi.org/10.1007/s42757-019-0047-5.

[54] Mohamadian, N., Ghorbani, H., Wood, D. A., Mehrad, M., Davoodi, S., Rashidi, S., Soleimania, A \& Kiani Shahvand, A., 2021. A geomechanical approach to casing collapse prediction in oil and gas wells aided by machine learning. Journal of Petroleum Science and Engineering, 196, 107811. Doi: https://doi.org/10.1016/j.petrol.2020.107811.

[55] Ghorbani H, Wood DA, Mohamadian N, Rashidi S, Davoodi S, Soleimanian A, Kiani Shahvand, A, Mehrad M., 2020. Adaptive neuro-fuzzy algorithm applied to predict and control multi-phase flow rates through wellhead chokes. Flow Measurement and Instrumentation. Nov 12:101849. Doi: https://doi.org/10.1016/i.flowmeasinst.2020.101849.

[56] Ranaee, E., Ghorbani, H., Keshavarzian, S., Ghazaeipour Abarghoei, P., Riva, M., Inzoli, F., and Guadagnini, A. 2021. Analysis of the performance of a crude-oil desalting system based on historical data. Fuel. Doi: https://doi.org/10.1016/i.fuel.2020.120046.

[57] Ghorbani, H., Wood, D.A., Mohamadian, N., Rashidi, S., Davoodi, S., Soleimanian, A., Kiani Shahvand, A. and Mehrad, M., 2020. Adaptive neuro-fuzzy algorithm applied to predict and control multi-phase flow rates through wellhead chokes. Flow Measurement and Instrumentation, 76, p.101849. Doi: https://doi.org/10.1016/i.flowmeasinst.2020.101849 .

[58] Rashidi, S., Mehrad, M., Ghorbani, H., Wood, D. A., Mohamadian, N., Moghadasi, J. \& Davoodi, S., 2021. Determination of Bubble Point Pressure and Oil Formation Volume Factor of Crude Oils Applying 
Multiple Hidden Layers Extreme Learning Machine Algorithms. Journal of Petroleum Science and Engineering. Doi: https://doi.org/10.1016/j.petrol.2021.108425.

[59] A. Todhunter, M. Crowley, M. Gholamisheverini, and F. Sartipi, "Advanced technological implementation of construction and demolition waste recycling," Journal of Construction Materials, vol. 1, no. 1, 2019, doi: https://doi.org/10.36756/JCM.v1.1.3.

[60] F. Sartipi, "Automatic sorting of recycled aggregate using image processing and object detection," Journal of Construction Materials, vol. 1, pp. 3-3, 2020, doi: https://doi.org/10.36756/JCM.v1.2.1.

[61] F. Sartipi, "A brief critical view on the carbon-conditioning of recycled aggregate using pressure chamber," Journal of Construction Materials, vol. 2, pp. 1-4, 2020, doi: https://doi.org/10.36756/JCM.v2.1.4.

[62] F. Sartipi and A. Sartipi, "Brief review on advancements in construction additive manufacturing," Journal of Construction Materials, vol. 1, pp. 2-4, 2020, doi: https://doi.org/10.36756/JCM.v1.2.4

[63] F. Sartipi, "Diffusion of Innovation Theory in the Realm of Environmental Construction," Journal of Construction Materials, vol. 1, pp. 4-2, 2020, doi: https://doi.org/10.36756/JCM.v1.3.2.

[64] A. Kandiri, F. Sartipi, and M. Kioumarsi, "Predicting Compressive Strength of Concrete Containing Recycled Aggregate Using Modified ANN with Different Optimization Algorithms," Applied Sciences, vol. 11, no. 2, p. 485, 2021, doi: https://doi.org/10.3390/app11020485.

[65] A. Gharizadeh, F. Sartipi, E. Ayoubi, and A. Severino, "The chemical reactor design configuration of $\mathrm{CO} 2$ concrete green solution," Journal of Construction Materials, vol. 1, pp. 2-5, 2020, doi: https://doi.org/10.36756/JCM.v1.2.5.

[66] F. Sartipi, "Dynamic data processing for building energy consumption," Journal of Construction Materials, vol. 2, no. 2021, pp. 2-4, 2020, doi: https://doi.org/10.36756/JCM.v2.2.4 . 